\title{
A dinâmica de múltiplos interferentes na atividade laboral: Estudo de uma comunidade tradicional
}

\author{
Hellen Silva de Azevedo \\ Manuel Vazquez Vidal Jr \\ Alexandre de Azevedo
}

A dinâmica de múltiplos interferentes na atividade laboral: Estudo de uma comunidade tradicional

\section{Resumo}

Com os objetivos de identificar os fatores dinâmicos que interferem localmente a realização da atividade pesqueira e aquícola da comunidade tradicional da Praia Rasa, Armação dos BúziosRJ, este trabalho propõe um estudo da dinâmica interacionista em ambiente pesqueiro e aquícola marítimo. Para isso foram utilizadas entrevistas individuais, no modelo semiestruturado, com aquicultores da Praia Rasa e aplicação de questionários com os pescadores artesanais da mesma praia, além da percepção das visitas in loco e a aplicação de análise de conteúdo ao material coletado. Conclui-se que os fatores de maior interferência da dinâmica da comunidade aquícola e pesqueira da Praia Rasa, Armação dos Búzios-RJ, estão relacionados ao turismo, a especulação imobiliária, as atividades petrolíferas da região, a submissão do trabalho ao capital e aos mitos e ritos desenvolvidos nessa comunidade.

Palavras-chave: Tradicional. Pesca. Aquicultura. Trabalho.

The dynamics of multiple interfering in labor activity: Study of a traditional community Abstract

With a view to identifying dynamic factors that affect locally the realization of fishing and aquaculture activities of Praia Rasa, Armação dos Búzios-RJ traditional community, this paper proposes a study of the interacting dynamics in fisheries and marine aquaculture environment. For this individual interview were used in semi-structured model with farmers of Rasa Beach and questionnaires with artisanal fishermen in the same beach, beyond the perception of the site visits and the application of analysis of content to the collected material. Conclude that the factors of greater interference of the dynamics of aquaculture and fishing community of Rasa Beach, Armação dos Búzios, Rio de Janeiro, are related to tourism, real estate speculation, the oil activities in the region, the submission of labor to capital and myths and rites developed in this community.

Keywords: Traditional. Fishing. Aquaculture. Work.

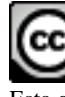




\section{Introdução}

São vários os fatores que podem interferir na realização de atividades laborais, alguns interferentes importantes são: as transformações urbanas, as tradições locais, as transformações provocadas pelo turismo, às provocadas pela produção industrial, os mitos e ritos de cada comunidade e a submissão do trabalho ao capital. Segundo Maciel, Lima e Lima (2013) as transformações no espaço urbano são realizadas a partir de formas, atividades, significados e práticas sociais que tornam cada processo particular em sua singularidade, tornando-se, desta forma, um determinado contexto perceptível. Associam-se os diversos elementos que compõem esta transformação com as imagens que a cidade transmite, sendo esta associação respaldada pela avaliação de três elementos ou componentes principais: identidade, significado e estrutura. A partir destes elementos as transformações de cenários podem ser analisadas e compreendidas, tornando as mudanças ambientais possíveis de serem observadas.

A atividade turística no Brasil cresce a passos largos, em 1970 o número de turistas vindos ao Brasil chegou a 249.900, já em 2012 este número alcançou a 5.676.843, montante que gerou uma Receita Cambial da ordem de 6,6 bilhões de dólares em 2012 (BRASIL, 2013). Embora o turismo, do ponto de vista econômico, seja algo muitas vezes positivo Coriolano (1998), alerta empreendedores, usuários, autoridades e gestores sobre o risco do ponto de vista social, cultural e ambiental que se faz, muitas vezes, presente no processo de exploração do turismo em ecossistemas e comunidades. Sendo assim, o turismo deve ser sempre visto sob uma ótica questionadora do desenvolvimento sustentável, lembrando sempre da existência de uma realidade dúbia, positiva e negativa, do turismo, onde sempre deve-se ter em mente o planejamento social e econômico (ALVARES, 2001).

No que se refere às questões industriais são diversas as transformações que esta atividade promove no espaço urbano, no caso de Armação dos Búzios um forte interferente é a Indústria de petrolífera. Herculano (2010) comenta que são diversas as interferências, positivos e negativos, oriundos da atividade industrial petrolífera, para este autor, as atividades de exploração e prospecção de petróleo geram grande impacto, pois possibilitam a obtenção de recursos vultosos ao mesmo tempo em que geram passivos ambientais difíceis de serem mitigados.

Já analisando as interferências causadas pela relação entre capital e trabalho Santos e Pessoa (2006) avaliam que o modo de produção capitalista tem promovido, desde o seu início, um processo de dominação sobre as classes trabalhadoras, muito além da questão de exploração salarial, modelando inclusive a visão de mundo dos trabalhadores, este estão sempre e crescentemente colocados a uma posição passiva, não permitindo que eles transformem a sociedade de forma que esta não seja mais dominada pelo capital. O capitalista é proprietário não somente do capital, mas também do trabalho, isto porque no trabalho o trabalhador realiza as atividades existentes sob o controle da lógica capitalista.

Quando avaliadas as questões múltiplas de interferências particularmente nas sociedades oriundas da gente do mar, é de se destacar as mais latentes como as questões simbólicas, mágicas e rituais, das quais se cobre, nas diversas culturas marítimas e nas relações do homem com o mar, sendo este simbolismo variável de acordo com a sociedade. Esta particularidade se faz presente na observação de que em algumas 
sociedades o mar é visto como um objeto de temor e em algumas regiões do Pacífico o mar é visto como um ambiente rico em vida, como um ser vivo que para nele adentrar é preciso com ele se conciliar. Nas sociedades ocidentais, estes mitos e ritos estão em processo de desaparecimento, se analisar sob uma ótica coletiva, mas não quando analisamos sob uma ótica individual (DIEGUES, 1999).

Este trabalho possui como objetivo geral a identificação dos fatores dinâmicos que interferem localmente a realização da atividade pesqueira e aquícola na comunidade tradicional da Praia Rasa, Armação dos Búzio-RJ e com os objetivos específicos de descrever a dinâmica dos mitos e ritos da comunidade pesqueira da Praia Rasa, Armação dos Búzios-RJ, analisar as relações capital trabalho na comunidade aquícola e pesqueira da Praia Rasa, Armação dos Búzios-RJ, identificar as dinâmicas da comunidade pesqueira da Praia Rasa, Armação dos Búzios-RJ e identificar o perfil organizacional da comunidade aquícola da Praia Rasa, Armação dos Búzios-RJ. Este trabalho propõe um estudo da dinâmica interacionista em ambiente pesqueiro e aquícola marítimo, justificável pela importância de se compreender a lógica de interações ambientais, pessoais e locais, como forma de planejamento de futuros investimentos nesses setores.

\section{Metodologia}

A metodologia de obtenção de dados para análise foi baseada em entrevistas individuais, no modelo semiestruturado, com aquicultores da Praia Rasa no município de Armação dos Búzios-RJ. Tais entrevistas foram direcionadas de acordo com o perfil do grupo e aplicadas aos 3 aquicultores em atividade (todos os aquicultores da praia) e analisadas por análise de conteúdo.

Também foi realizada aplicação de questionários individuais com pescadores da Praia Rasa, no município de Armação dos Búzios-RJ, totalizando 6 entrevistados. Os questionários foram direcionados de acordo com o perfil deste grupo. A seleção dos entrevistados, tanto pescadores quanto aquicultores, ocorreu de acordo com o tipo e objetivo do estudo, estabelecendo-se o tipo da amostra, em função das condições dos atores que sejam essenciais, segundo o investigador, para o esclarecimento do assunto em foco (TRIVIÑOS, 1992).

Foi utilizada metodologia de amostragem proposital, na aplicação dos questionários com os pescadores, este tipo de amostra é não probabilística e consiste em escolher com cuidado os casos que devem ser incluídos na amostra, desenvolvendo amostras que são satisfatórias de acordo com as necessidades (SELLTIZ et all., 1987). No caso desta pesquisa foram utilizados os seguintes critérios: pescadores que estão atuantes na pesca mesmo que realizando outra atividade profissional paralela, pescadores que atuam na pesca somente na Praia Rasa, pescadores que possuem barcos movidos a remo ou não, inclui-se nesta amostra um pescador que possui o único barco movido a motor da praia. Optou-se também por escolher um perfil etário variado, devendo-se destacar que não se encontrou pescadores com idade inferior a 45 anos, utilizou-se o perfil etário variante entre 45 e 71 anos. A diversidade de perfil foi utilizada na tentativa de se questionar o público mais diferente possível, para desta forma se obter uma amostra que seja representativa dos pescadores da Praia Rasa.

O tamanho da amostra, na aplicação dos questionários com os pescadores, foi 
definido utilizando saturação teórica (6 entrevistados) e a avaliação dos dados foi realizada por análise de conteúdo, onde organizou-se e analisou-se os dados coletados.

Segundo Calvosa (2010) não se pode entender nenhuma empreendimento como uma ilha ou um sistema completamente fechado. Os empreendimentos estão rodeados e interagindo com uma diversidade plural de ambientes e objetos. Para que os negócios de uma organização possam ser realmente efetivados é necessário um relacionamento de dependência saudável como uma diversidade de agentes que lhe proporcionam receber, manipular e transformar matérias-primas ou insumos, e também modificar, desenvolver e aprimorar esses materiais para se gerar produtos, que em um momento posterior, serão comercializados com outras pessoas ou outras empresas, gerando lucratividade e, por conseguinte a sobrevivência da organização. Este seria o ambiente mais próximo de um microambiente. Mas além destas pressões, um microambiente pode sofrer pressões de fora, forças que não podem ser controladas. Essas forças externas podem ser variadas, mas sempre determinantes.

Tendo o exposto em vista, as análises dos dados foram múltiplas, sendo levado em conta o contexto dos atores, da rede que sustenta a pesca artesanal e a aquicultura familiar, ou seja, o setor de insumos, os pescadores, o transporte, o comércio, os consumidores; o ambiente organizacional (publicações, associações, colônia de pesca, etc.) e o ambiente institucional (legislação ambiental, regras de comércio, etc.) no município de Armação dos Búzios-RJ.

Foram utilizados, portanto, para a coleta de todos os dados: questionários com pescadores, entrevista com aquicultores, além da percepção nas visitas in loco, realizadas entre os meses de julho de 2012 e fevereiro de 2014. Estes instrumentos serviram como ferramentas para obtenção de resposta para a questão: Quais são os fatores de maior interferência na dinâmica laboral da comunidade aquícola e pesqueira da Praia Rasa, Armação dos Búzios-RJ?

\section{Resultados e discussão}

\subsection{Contextualização da comunidade pesqueira e aquícola}

\subsubsection{Dinâmica da comunidade pesqueira}

A comunidade de pescadores, que realizam suas atividades na Praia Rasa, Município de Armação dos Búzios - RJ, está organizada em uma colônia, a Colônia de Pescadores de Armação de Búzios-RJ (Colônia Z-23). A associação dos pescadores à colônia é total, e aparece de forma unanime nas seis entrevistas com os pescadores. Esta colônia se caracteriza como uma forma de organização institucional, que possibilita relações comerciais mais amplas e maior organização com os seus pares. Segundo Tolbert e Zucker (1998) a institucionalização de forma integral de uma estrutura presente é proveniente da pouca resistência de determinados indivíduos ou grupos de oposição, assim como da promoção e relação de apoio de indivíduos ou grupos que se colocam na posição de defensores de determinadas alterações. Também é importante definir que cada estrutura de organização possui seu próprio meio de realizar interpretações, inclui-se a este, as crenças e valores tidos como verdadeiros e que se apresentam com certa estabilidade no seu interior, o que indicaria um sistema cognitivo 
compartilhado.

As interferências promovidas pelas atividades turísticas e petrolíferas, com utilização de royalties, na comunidade, também proporcionam um visível sectarismo da população da Praia Rasa. Em visita a comunidade, utilizando-se, portanto, dados da visita in loco, é fácil observar a divisão arquitetônica existente nesta região. Algumas áreas tomadas por condomínios com casas de alto luxo contrastando com outras regiões de casas bem mais humildes. Os pescadores que realizam a atividade de pesca, hoje moram em locais cercados por casas de padrões econômicos diferentes das suas, embora ainda na Praia da Rasa. Este fato pode ser traduzido como uma interferência forte da especulação imobiliária e do turismo na região transformando a realidade dos pescadores do local e dificultando, em alguns momentos, a realização da atividade de pesca. Segundo dados do IBGE (2010) o município possuía 17.842 domicílios, sendo $37 \%$ desses de uso ocasional, o que exemplifica o forte perfil turístico local.

Aqueles indivíduos que transformam o uso do solo urbano tornam singulares as diversas áreas de uma cidade, colocando em prática estratégias que supervalorizam essas áreas, que supervalorizadas são então ocupadas por indivíduos de maior poder aquisitivo, geralmente pessoas que possuem renda superior a três salários mínimos. Nestas condições, ocorre uma valorização do espaço nas cidades que está diretamente ligada à amplificação das diversas formas de utilização do solo urbano, indicando e favorecendo cada dia mais a segregação sócio-espacial, além de dilatar a desigualdade, tendo em vista a reprodução maciça do capital, o que, por conseguinte, também gera desigualdade social, discutida em Lefebvre (1999; 2008), Castells (2000), Harvey (1980).

Apesar de morarem afastados do mar, estes pescadores não veem como um grande empecilho a distância para realizar atividade laboral pesqueira, fato que pode ser confirmado nos questionários onde cinco dos seis pescadores responderam não ser a distância um entrave, porém deixam claro que prefeririam estar morando próximos aos locais onde trabalham. Para Alvim (2012) o entendimento dos valores de pertencimento de um determinado indivíduo a um determinado espaço físico, assim como a valorização social que tais conferem aos objetos da terra, ao espaço e ao meio social e ambiental, deve ser amplamente respeitado. Ficando claro que é de extrema relevância o entendimento dos valores humanos e também os ambientais, que justificam e dão sentido às condições de vida dos pescadores em nível social, econômico e ambiental, incluindo-se a este último os impactos sofridos que afetam e envolvem diretamente a vida dos pescadores num contexto histórico recente.

Observa-se também que as interações e as conversas dos pescadores são sempre animadas e relacionadas à atividade diária de pesca, como o aumento da maré, a quebra de barcos e questões mecânicas, esta última relacionada ao único barco a motor que realiza a atividade exclusiva de pesca, fatores estes que indicam a apreciação da atividade pelos pescadores, que compreendem a atividade laboral como parte de seu lazer além de se preocuparem com a manutenção dos seus instrumentos de trabalho e renda. Nessas conversas podem-se escutar frases como: "Tem que arrumar logo isso [o barco]", "Hoje [o mar] tava batendo muito" e "Como foi hoje?" (uma referência ao volume de pescado capturado). Segundo Dumazedier (2008) o entendimento da palavra lazer pode ser bem amplo, para o autor lazer é um conjunto de diversas ocupações das quais o indivíduo pode dispor e realizar por face do seu livre arbítrio, esta escolha pode 
incluir o repouso, a diversão, a recreação, o entretenimento, pode ser para desenvolvimento de uma formação desinteressada, ou uma participação voluntária em sociedade, ou para o desenvolvimento de sua capacidade criadora, atividades que são exercidas não apenas motivadas pelas obrigações, sejam elas sociais, familiares ou até mesmo profissionais. Desta forma, o lazer é uma escolha particular e individual, ajudando o indivíduo a realizar tarefas que não se apresentam como obrigatórias nos seus ambientes rotineiros, sendo motivada pela busca do prazer e satisfação.

Outro fator que pode colaborar para a manutenção da atividade, mesmo morando afastado do local de pesca, é a introdução de meios de transporte de pouco custo como pequenas motos que facilitam este transporte, fator sempre observado nas visitas in loco, alguns pescadores chegam para pescar de bicicleta, pequenas motos, ou a pé. Também pode-se observar um desejo por aumentar a renda através do crescimento da pressão de pesca pelo aprimoramento da técnica e aumento dos barcos, com introdução de atividades como arrasto de camarão, barcos com motor e atividade de maricultura, os dois primeiros realizados por um pescador que utiliza barco a motor nas suas atividades de pesca, já a maricultura observada na ida a Associação dos Trabalhadores na Aquicultura (A.T.A.), que também realiza seus processos produtivos na Praia Rasa.

A comunidade de pescadores da Rasa possui características muito peculiares. Os barcos ancorados na praia são, em sua grande maioria, pequenos e movidos a remo, a pescaria é realizada nestes barcos com anzol e em mar aberto, fatos observados nas visitas ao local. Tal arte de pesca, de forma puramente artesanal, é vista em raras comunidades pesqueiras do país. Por tais motivos fica evidente a riqueza de características e particularidade desta comunidade, que ainda pesca como há milhares de anos atrás outras comunidades pescavam, isto define tal comunidade como tradicional. Segundo Ramalho (2007) a parca existência de recursos e consequentemente a agregação de pouca tecnologia contemporânea, que colabore para um resultado mais eficiente no que tange a obtenção de recursos pesqueiros na atividade de pesca a qual tais pescadores estão inseridos, vincula-os a ideia de pesca artesanal, que por sua vez se relaciona com a ideia de artesão, que seria definido como pessoas que possuem habilidades e talentos aflorados nos momentos precisos. Estes momentos podem ser durante a pesca ou até mesmo durante a confecção dos seus instrumentos de trabalho.

A comunidade, de uma forma geral, também utiliza a praia para realizar a pesca de caranguejo em pequena escala, demonstrando que outros moradores também utilizam este ambiente como fonte de recursos. O turismo é frequente e na Praia Rasa, podemos observar a prática de esportes como o kitesurf e a presença de banhistas na beira do mar, situação mais rara. Segundo um dos informantes, o convívio com os turistas não atrapalha a atividade pesqueira, porém não são utilizadas interações econômicas diretas dos turistas com os pescadores, como a utilização de barcos dos pescadores para passeios turísticos. Um dos informantes afirma que a questão da fragilidade do barco e da segurança para realização desses passeios, juntamente com a questão da procura ser esparsa são os fatores que inibem a realização deste tipo de atividade na região.

$\mathrm{O}$ avanço dos turistas gerou um distanciamento dos pescadores, não sendo, hoje, possível observar um núcleo de moradias de pescadores em uma região bem definida, embora quase em sua maioria continuarem morando na Praia Rasa. Isto indica a forte especulação imobiliária na região, onde o número de condomínios é grande e contrasta com a existência de casas humildes, por vezes uma realidade luxuosa vizinha de ruas 
onde a realidade é de poucos recursos econômicos.

É importante deixar claro que apesar das transformações urbanas não serem definidas apenas por questões de crescimento da população em determinada região, observa-se que o crescimento populacional é também fator de interferência da disponibilidade de território e no valor do metro quadrado em determinada região. No caso de Armação dos Búzios dados do IBGE (2010) mostram que o crescimento populacional nos últimos anos tem sido superior, em proporções, ao crescimento populacional brasileiro e do estado do Rio de Janeiro como observado no Gráfico 1. Este crescimento é provocado pela aceleração da economia, pelo aumento do turismo na região e também pelo crescimento do setor petrolífero, os dois fatores geradores de emprego direto e indireto que fazem aumentar a população nessa região, gerando especulação imobiliária, tendo em vista a maior procura por casas e apartamentos em relação a oferta, desses na região.

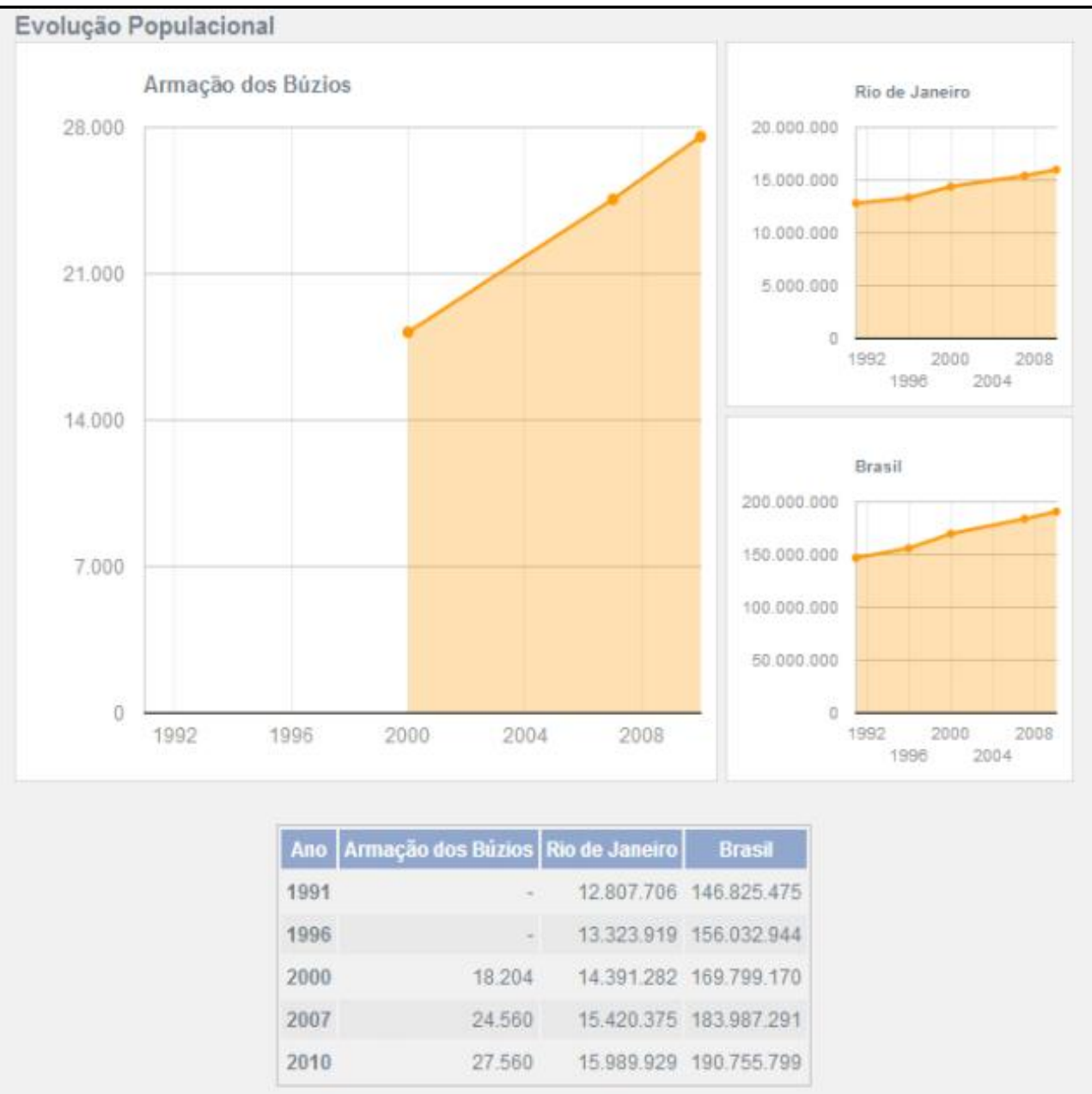

Gráfico 1: Evolução da população em Armação dos Búzios-RJ do ano de 1991 até o ano de 2010 e seu comparativo com a evolução populacional do estado do Rio de Janeiro e com o Brasil no mesmo período. Fonte: IBGE (2010).

Uma das características artesanais da comunidade pesqueira é a construção pelos próprios pescadores, dos barcos que utilizam para pescar. Quando questionado de quem fazia os barcos utilizados para a pesca um dos informantes afirma: "É nós mesmo que 
faz". Os produtos obtidos pela pesca são vendidos para uma peixaria localizada na Praia Rasa, a peixaria do André, esta peixaria foi indicada pelos seis pescadores questionados como destino do pescado capturado por esses, sendo que dois dos pescadores questionados também indicaram que enviam outra parte para o município de Cabo FrioRJ.

Outro fator que está presente é o fato de grande parte dos filhos dos pescadores, apesar de terem uma forte relação afetiva com o mar, demonstrarem menor interesse pela atividade de pesca, o que se apresenta como uma grande barreira para a continuação da atividade pesqueira. Salienta-se neste contexto que os pescadores entrevistado possuem idade variada entre 45 e 71 anos. O processo de queda na atividade pesqueira, provocada pela diminuição da disponibilidade de pescado ( processo iniciado, segundo os seis pescadores questionados, em 1990), se relaciona diretamente com a diminuição dos motivadores dos filhos dos pescadores para seguirem nesta atividade laboral.

\subsubsection{Perfil organizacional da comunidade de aquicultores}

Os pescadores-aquicultores são pertencentes, também, à comunidade da Praia Rasa, estes se organizam pela Associação dos Trabalhadores na Aquicultura (A.T.A.). Esta comunidade aquícola é formada por indivíduos que realizavam atividade laboral somente de pesca, mas que se viram com dificuldades econômicas e financeiras e decidiram incorporar a aquicultura, com produção de ostras e mexilhão, na sua realidade laboral, como forma de obtenção de recursos econômicos e financeiros.

Uma interferência forte dentro das atividades aquícolas da região é a Prefeitura Municipal de Armação dos Búzios-RJ, que oferece colaboração através de projetos de estímulo a pesca e recentemente a aquicultura marinha (maricultura), fornecendo material para a montagem e expansão da aquicultura local. Outro órgão que interfere nesta dinâmica é a Fundação Instituto de Pesca do Estado do Rio de Janeiro (FIPERJ), com a colaboração técnica para a montagem e manutenção das linhas de produção de mexilhão e ostra. Os dois órgão de fomento citados foram indicados pelos 3 aquicultores entrevistados, representando uma unanimidade.

O grupo de aquicultores da Praia Rasa é composto, atualmente, por três famílias atuantes no processo produtivo. As questões vinculadas ao maior ganho financeiro e a disponibilidade de peixes são os principais estímulos para os pescadores se transformarem em aquicultores, modificando, desta forma, a realidade econômica e financeira, sua e de suas famílias. Esses dois fatores foram 1 citados nas entrevistas pelos três aquicultores. Um dos informantes entrevistados afirmou: "Para pescar aqui tá difícil, qualquer um que você chegar ali [Praia Rasa] e perguntar, tem outra profissão".

Nesta comunidade fica clara a existência de um discurso ecológico marcante, voltado para a preservação ambiental, presente em longas falas sobre temas como poluição, interferências ambientais provocadas pela indústria do petróleo, dos três aquicultores entrevistados, porém tais discursos estão sempre relacionados às interferências destes fatores nas questões produtivas aquícolas. O discurso ecológico é facilmente disseminado nessa comunidade, pois estes, atualmente, pescadoresaquicultores e que eram antes apenas pescadores, observaram dentro de uma linha 
histórica temporal a diminuição drástica do pescado na região, fonte de sua renda, fator observado na fala do aquicultor: "A previsão do homem é em 50 anos acabar o pescado". Hoje, estas pessoas se preocupam de forma extremamente marcante e simbólica com a preservação do ambiente que lhe fornece o sustento, esta preocupação ambiental torna-se, neste contexto, um caminho obrigatório seguido pela maioria dos indivíduos deste contexto.

Tais aquicultores, estão limitados por diversos fatores que podem impedir o crescimento desta atividade ou um processo produtivo mais efetivo e eficaz. A interferência dos barcos de turistas que utilizam como rota, áreas do cultivo de mexilhão e ostras, atrapalha o processo produtivo, tornando a gestão da produção interligada a fatores externos a empresa, fator observado nas visitas in loco, com frequência diária. Outras limitações se apresentam mais direcionadas para questões financeiras e econômicas. Atualmente, os aquicultores, dependem de recursos públicos municipais para ampliação das suas atividades, o que demonstra, falta de recurso financeiro de reserva e pouca autonomia empresarial, além de indicar um forte gargalo: o aumento da produção limitada pela incapacidade de aumentar a linha de produção ou espaço produtivo. Esta limitação se mostra recorrentemente em todas as entrevistas, indicando que é um dos gargalos mais percebidos pelos aquicultores.

Pessoa (2003) afirma que os diversos entraves causados pelo excesso ou pela escassez de capacidade de produção, são presentes em todas as empresas, isto se dá principalmente quando se observa uma variabilidade natural na demanda proveniente dos ciclos econômicos. Tais problemas podem ser minimizados quando se realiza uma gestão de recursos mais ponderada, dimensionando o real custo e o benefício de se realizar um investimento em tecnologia e em recursos que aumentem a produção por espaço e por recurso, em detrimento do aumento das linhas de produção. Antes de se investir em tecnologia é preciso primeiro identificar qual é o verdadeiro gargalo do processo produtivo.

\subsection{Relação capital x trabalho}

O dinheiro rebaixa todos os deuses do homem e transforma-os em mercadoria. O dinheiro é o valor universal e auto-suficiente de todas as coisas. Por conseguinte, destituiu todo o mundo, tanto o mundo humano como a natureza, do seu próprio valor. O dinheiro é a essência alienada do trabalho e da existência do homem; esta essência dominao e ele presta-lhe culto e adoração. (MARX, 1964, p. 70).

Numa avaliação da comunidade pesqueira e aquícola da Praia Rasa, Armação dos Búzios-RJ, observa-se um enfrentamento diferente da relação capital trabalho, um no contexto dos aquicultores e outro no contexto dos pescadores. Para esta análise é importante destacar que os agentes que hoje realizam a atividade aquícola na Praia Rasa, já foram pescadores que pescavam na mesma praia, e que os pescadores que hoje pescam na Praia Rasa, também, em quase totalidade, realizam outras atividades como fonte de obtenção de recursos financeiros e econômicos. Os aquicultores atuantes na Praia Rasa pertencem a uma classe etária variante entre 25 e 45 anos sendo, portanto, pertencentes a uma geração posterior a da maioria dos pescadores atuantes, hoje, na Praia Rasa. 
Santos e Pessoa (2006) destacam que há, no contexto capitalista histórico referente ao modo de produção predominante, uma marcada dominação da classe trabalhadora. $O$ trabalhador está colocado a uma posição de dominação que vai além da questão de exploração salarial, que interfere também na visão de mundo do trabalhador, esses estão colocados a uma posição passiva, de forma que não se possibilita a transformação da sociedade para uma realidade não dominada pelo capital. $\mathrm{O}$ modo capitalista é o dono do capital e do trabalho, pois no trabalho o trabalhador realiza, sobre o controle do capital, as atividades necessárias.

Dentro deste contexto, pode-se perceber que a interferência capitalista na escolha de uma nova atividade laboral, como forma principal de obtenção de remuneração, por parte dos pescadores, é marcante, isto porque apesar de gostarem da atividade pesqueira, a falta de pescado na região, que ocasionou um menor aporte lucrativo para a atividade, forçou os pescadores a introduzirem nova atividade laboral, relacionada principalmente ao setor de construção civil, petrolífero, segurança particular e serviços gerais e hoje, utilizam a pesca como forma de complementar a remuneração auferida nestas outras atividades, mesmo estes tendo com o mar uma forte relação afetiva. Estas questões são unanimidades entre os pescadores entrevistados e também podem ser observadas nas falas desses informantes, quando dizem: "Não tem como parar de pescar não" e "Não dá para viver só da pesca”, em uma referência a pouca quantidade de pescado e dificuldade de obtenção de remuneração com a atividade pesqueira.

A relação desses pescadores com outras fontes de renda, principalmente ligadas à indústria e aos serviços, coaduna-se com o exposto e apresentado no Censo 2010, que indica que o Produto Interno Bruto (PIB) do município de Armação dos Búzios é composto em sua grande maioria pela indústria (1.146.258), seguida pelo setor de serviços (587.168) e pelo setor agropecuário (3.088). Comparados com a realidade do estado do Rio de Janeiro e do Brasil, observa-se uma inversão, onde no município a indústria abocanha maior fatia do PIB, já no estado e no país, quem representa maior fatia do PIB é o setor de serviços IBGE (2010). Isto indica a forte influência que a indústria de petróleo tem no município e que reflete diretamente nas opções de emprego e obtenção de renda dos trabalhadores pesqueiros (Gráfico 2).

Para Marx (2004), nessa condição submissa do trabalho ao capital, o trabalhador vira uma mercadoria, se torna um ser estranho a si mesmo, apenas uma forma de obter sua existência individual. Porém um perfil menos submisso pode ser observado no contexto da Praia Rasa: os aquicultores. Esses trabalhadores, antes pescadores, quando observaram a diminuição de pescado e da lucratividade pesqueira, não migraram parcialmente para atividades não relacionadas ao mar, objeto de grande afeição por eles, incorporaram outra atividade de obtenção de remuneração que se associa diretamente com o mar: a maricultura. Um fator que impediu a introdução generalizada, de mariscos foi o fato desta atividade ainda se apresentar em fase de instabilidade e pouca lucratividade, comum a qualquer microempreendimento em fase inicial. Para estes indivíduos, hoje aquicultores, o capital foi motivo de menor interferência para escolha laboral, fato observado nas frases ditas pelos informantes, aquicultores, na entrevista: "A gente vive isso aqui" (uma referência a viver no mar), "Não tinha como ficar longe [do mar] não”. 


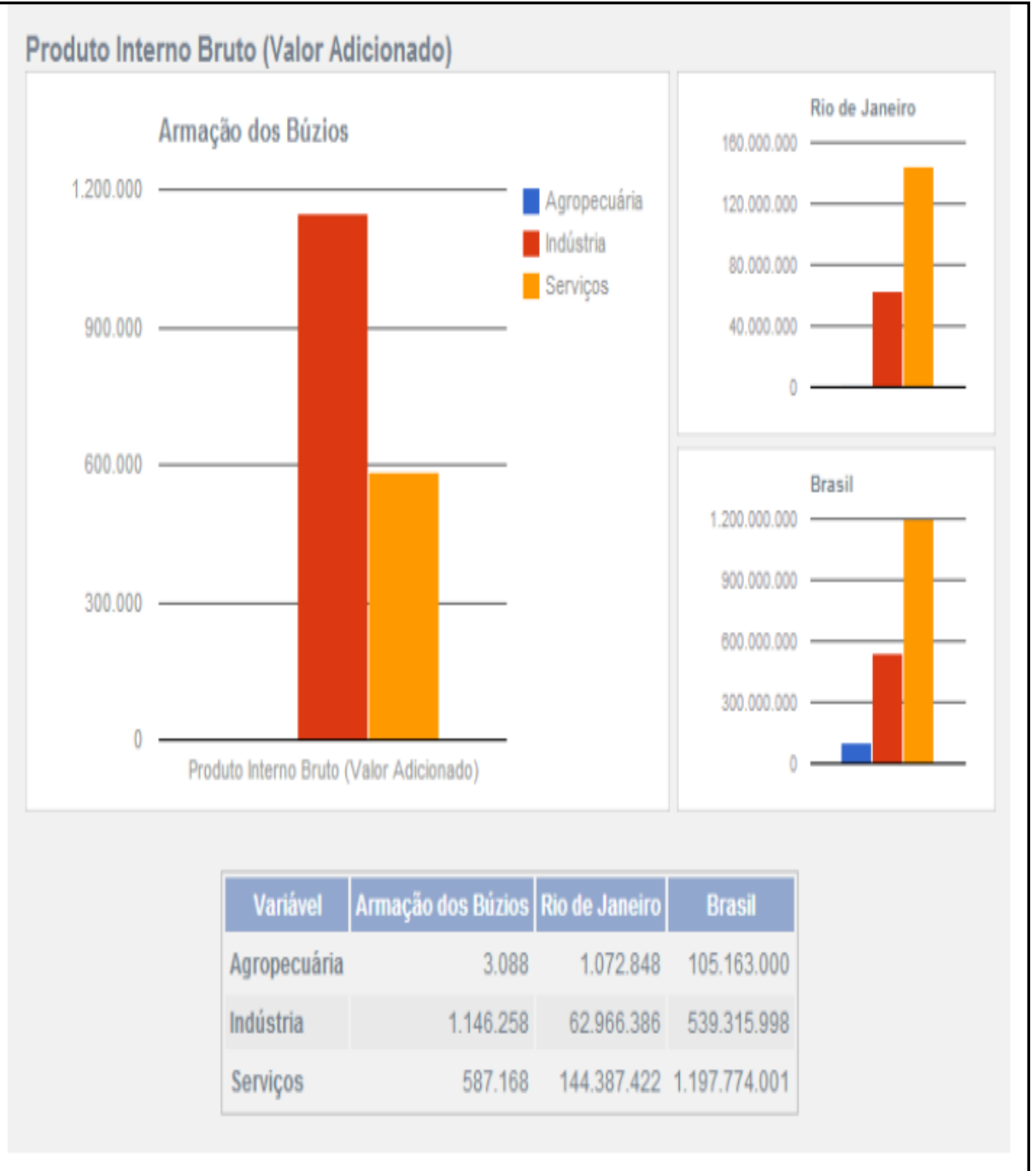

Gráfico 2: Produto Interno Bruto (PIB) do município de Armação dos Búzios em comparativo ao estado do Rio de Janeiro e ao Brasil. Fonte: IBGE, 2010.

É de se destacar que o homem traz consigo ambições, sentimentos, expectativas, se envolve, almeja ascensão na atividade que realiza. É necessário deixar a ideia de que todo o ser humano trabalha somente para obtenção do salário. É necessário abandonar a ideia de que pelo salário rejeita seus sentimentos, não se frustrando com o pouco ou o não crescimento, que não se entristecem com a promoção da alienação dos trabalhadores com a simples cobrança por tarefas, sem orientação sobre as questões motivadoras principais, negando informações e tratando o trabalhador como uma mera peça do sistema produtivo. $\mathrm{O}$ trabalhador é um ser integrado e não divisível com direito a sonhos de estima e realizações próprias (MORETTI, 2005).

\subsection{Dinâmica dos mitos e ritos na comunidade da Praia Rasa}

Para Lévi-Strauss (1997) nem o mito nem o rito podem ser entendidos, de forma simplória, como lendas extraordinárias, mas sim como uma forma de se organizar a realidade, tomando como ponto de partida a estrutura sensível, enquanto tal. LéviStrauss (1997) com o intuito de explicar o que compõe o mito, organiza quatro 
diferentes estruturas, que se apresentam de forma mais marcante, são elas; (1) a função organizativa, o mito organiza as relações sociais, tanto as de parentesco, como as de troca, (2) a de poder, (3) a de identidade, (4) a de sexo. Desta forma, ocorre a legitimação e garantia a permanência de um sistema tido como complexo, que abrange tanto as proibições como as permissões, ocorrendo também uma função que compensa, sendo o mito uma espécie que funciona como um tipo de narrador de algo que ocorreu no passado, e que nega o presente, servindo, o mito, para duas coisas: gerar uma situação onde o humano é compensado por algum tipo de perda que possa ter ocorrido com ele, assim como para, garantir para o humano que aquele erro que foi cometido no passado, no presente já se apresenta corrigido. Desta forma, ocorre um movimento no sentido de tornar a visão mais estabilizada e regularizada da natureza e da vida comunitária. Já o ritual pode ser entendido, por Lévi-Strauss (1997) como sendo o modo pelo qual as coisas são ditas, em comparação com o mito que seria definido como sendo o que dizem as palavras. A pura essência do rito estaria assim entendida como sendo possuidora de características continuístas e obsessivas, em comparação com o pensamento mítico que age, segundo Lévi-Strauss (1997), no sentido oposto, sendo este um operador de processos descontínuos. Na Praia Rasa os mitos e os ritos estão atuando em conjunto, os ritos como exteriorização da experiência e os mitos como a transformação dos objetos e ações em modelos, a fim de trazê-los para a realidade. Os ritos são observados na confecção dos barcos, na tecnologia empregada no momento de se pescar, neste caso com barcos pequenos, movidos a remo e pesca em anzol, já os mitos no sentido de frases como: "A pesca aqui é muito rústica" e "Aqui tem pouco peixe".

$\mathrm{Na}$ comunidade de pescadores da Praia Rasa as "teorias" tradicionais (provenientes do empirismo ou míticas) construíram a base da chamada arte de pesca. Atualmente os pescadores, de uma forma geral e também na Praia Rasa, absorvem informações científicas que contradizem parte das informações tradicionais. Esta tensão se tornou ainda maior quando eles adotaram uma nova atividade econômica (aquicultura) apresentada pela academia ou por extensionistas. Hoje, e os pescadores tentam encaixar esse pacote tecnológico com seu conhecimento tradicional, neste caso o tradicional aqui se define como a prática, ou parte da prática executada no início da atividade local. Por ser um processo recente, a percepção do pesquisador pode ser dificultada pela própria dificuldade do pescador que ainda constrói esse novo universo.

Para Lévi-Strauss (1997) a classificação é baseada em um duplo princípio: universalização e particularização. Quando se pensa em um objeto, o indivíduo realiza dupla atitude, ao mesmo tempo em que se singulariza o objeto, tomando este como o único no mundo, também realiza um movimento no sentido de universalizá-lo como espécie. Quando se realiza a universalização está se estendendo o conjunto inicial a grupos e domínios exteriores. Para Lévi-Strauss (1997) é a sociedade que se manifesta e pensa dentro do indivíduo, funcionando como um operador lógico, a partir deste funcionamento o esquema de classificação de domínios de natureza diversa. Por este agrupamento o objeto, na figura de operador lógico, absorve classificações de natureza diversa, podendo interligar uma categoria a outra, assim como a mitos, a história, podendo realizar o operador a passagem tanto para o concreto e individual quanto para $o$ abstrato e sistemas de categorias, o que permite começar a distinguir o pensamento dos povos "selvagens" e o pensamento científico. Os povos selvagens realizam a construção 
dos seus conceitos por meio das características sensíveis, sendo este pensamento mais concreto, já o pensamento científico se baseia em conceitos mais abstratos. Na comunidade da Praia Rasa esta dinâmica também pode ser percebida, a pesca, na concepção do pescador, absorve classificação de natureza múltipla, passando este objeto (a pesca) a características sensíveis, do pensamento concreto: "tem pescado", “ diminuiu a quantidade de peixes", "barco a remo", "pesca em anzol”.

No caso da comunidade de pescadores em estudo (Praia Rasa) ambos os conceitos são visíveis, não ocorrendo constantemente à dicotomia (sensível/ concreto) sugerida. $\mathrm{O}$ pescador possui intima relação com o mar, extraindo dele o sustento e elementos para criar sua cultura e seus mitos, entretanto o pescador não é mais um colono e sim um homem da urbe, tendo em vista a inclusão das dinâmicas urbanas, como meios de transporte motorizados, pensamentos políticos, ideias sobre questões monetárias, financeiras, econômicas, as duas últimas presentes em quatro dos seis questionários aplicados aos pescadores, e a primeira frequentemente observada nas visitas in loco. Além disso, a academia passou a frequentar e a desconstruir os mitos, com pensamentos concretos, na aplicação de técnicas para aprimoramento da prática pesqueira, realidade pouco observada na comunidade da Praia Rasa. Assim pode-se inferir que os pescadores constroem pensamentos nos dois polos sugeridos, sensível e concreto. De certa forma observam-se elementos de grupo selvagem e de homem moderno na comunidade da Praia Rasa.

Para Lévi-Strauss (1997) os mitos e os ritos, oferecem como valor principal, terem mantido resíduos, até as épocas atuais, de modos de se observar e de se refletir que continuam adaptados à novas formas e tipos, provenientes das formas de se organizar e especular o mundo sensível. É importante deixar claro que a ciência do concreto não se deu de forma menos científica, não sendo seus resultados menos reais. Tomando como partida a forma de classificação baseada na sensibilidade, o pensamento pode se retirar de situações caóticas, se autocorrigir e se tornar cada dia mais complexo.

Nesse aspecto é interessante notar que os pescadores, da Praia Rasa, utilizam na percepção do clima, o empirismo: "deste lado vem à chuva", "[Tal] ave voa antes da tempestade”, o mito, nesta comunidade é percebido em frases como "no dia de [tal] santo não chove”, já o conhecimento científico está disponível nas diversas mídias que informam condições climáticas. Todos esses elementos (informações) são utilizados, às vezes simultaneamente, para a tomada de decisão. Neste ponto é interessante observar que não só o empirismo e os mitos estão presentes, como eles transpassaram do sistema de transmissão de conhecimento pela oralidade e atualmente constam de material impresso e em mídia digital, utilizados em raras oportunidades pelos pescadores da Praia Rasa.

Ainda no que se refere aos pescadores da Praia da Rasa, é significativo lembrar que numa escala de poucas gerações a arte tradicional de pesca, transmitida oralmente pelos mais velhos, foi primeiramente questionada pela ciência. Esta, a classificou como empírica e mesmo mítica. Em um segundo momento a ciência se preocupou em mostrar que parte do conhecimento (arte) poderia ser validado. Ainda vivemos esta etapa. O pescador que viu sua crença na arte ser abalada pela ciência, depois viu a ciência se reformar. A busca pela "verdade" constrói e derruba paradigmas, mas os homens que vão arriscar sua vida no mar se sentem mais seguros agarrados a sofismas do que a novos paradigmas cheios de reticências. Isto é facilmente comprovado pela observação 
local das técnicas que os pescadores ainda utilizam na Praia Rasa para pescar. A pescaria nesta praia é realizada de forma tradicional, como há muitos anos atrás, com barcos a remo e com pesca em anzol, demonstrando que pouco da ciência foi permeada na pesca desta localidade.

A grande distinção que pode ser traduzida na relação entre arte da pesca e ciência, é o fato de que a ciência trabalha através de conceitos, já a arte trabalha utilizando-se de signos, sendo neste caso, que o principal objetivo é injetar ordem tanto sobre a contingência, como sobre os pontos em que se desviam as normas dos elementos do mundo, estando este contexto, envolvendo tanto os que estão ligados ao pensamento científico quanto um bricoleur, está a arte no caminho médio entre o conhecimento científico e o pensamento mágico. Lévi-Strauss (1997), com isto, quer trazer à tona as leis que comandam a manifestação do espírito humano e causar um rompimento com a constante dicotomia entre o saber que é denominado arcaico e o denominado moderno, romper com a dicotomia entre pensamento mágico e científico e entre arte e ciência. Estariam, então, os pescadores da Praia Rasa no caminho medial entre o pensamento científico e o pensamento mágico, sendo estes dois não dicotômicos, pois perpassam o saber arcaico, da pesca com anzol em barcos movidos a remo, e também esbarram em saberes científicos, da utilização de previsões de tempo para ida ao mar para pescar.

Na comunidade de pescadores da Praia Rasa pode-se perceber que os diversos estágios citados (pensamento mágico, científico, pré-científico, bricoleur) podem ser vistos, raramente isolados e comumente mesclados na construção da relação com a pesca e com a própria comunidade. Ao relatar uma situação cotidiana (em relação à pesca propriamente dita), o pescador da Praia Rasa tende a explica-la para o pesquisador. Percebe-se nessa explicação que o discurso se assemelha a um quebra cabeça incompleto, que vai sendo preenchido com informações científicas, míticas e tradicionais. Onde o importante é dar sentido ao fato narrado, fazendo com que ele tenha uma origem numa relação causal. Cabe questionar se o conhecimento tradicional e empírico é real ou se é a perpetuação do pensamento mágico. Mesmo o que pode ser chamado de informação científica precisa ser vista em detalhes. Sendo assim, o pescador da Praia Rasa sofre interferências míticas e ritualísticas de uma gama de fatores internos e externos, históricos e do presente.

Mito se expressa na Praia Rasa, como um tipo de narrativa de características permeadas de símbolos, de uma determinada cultura, que tem o intuito de explicar o entendimento de realidade, assim como os seus acontecimentos principais, utilizando-se de deuses, semideuses e heróis. O rito se expressaria na Praia Rasa, através do modo pelo qual se colocaria em ação o mito na vida do pescador, através de danças, orações e sacrifícios, neste caso os pessoais. Estes identificados nos discurso orais dos pescadores e aquicultores da Praia Rasa, assim como presentes no simbolismo de suas atitudes e de seus comportamentos.

De uma forma menos ortodoxa, pode-se considerar que a comunidade de pescadores (em geral e na praia da Rasa, particularmente) desenvolveu mitos e ritos. Para o pesquisador é fácil perceber que são mitos algumas inferências que os pescadores fazem acerca do clima futuro próximo, entretanto algumas festividades que chegaram aos tempos atuais podem ter sua história associada a mitos que não mais são narrados. Outra situação em que o pesquisador pode não perceber o mito/rito é no caso da 
procissão marítima, uma vez que é uma festa que está dentro das formas de manifestação do catolicismo no Brasil, mas que tem paralelo com manifestações semelhantes em outras culturas e outras religiões, fazendo perceber que o ambiente (mar) é lido de forma semelhante em culturas diferentes.

\section{Conclusão}

Conclui-se que os fatores de maior interferência da dinâmica laboral da comunidade pesqueira e aquícola da Praia Rasa, Armação dos Búzios-RJ, estão relacionados ao turismo, a especulação imobiliária, as atividades petrolíferas da região, a submissão do trabalho ao capital e aos mitos e ritos desenvolvidos nesta comunidade.

No que se refere à relação capital/trabalho, os indivíduos que se mostraram mais submetidos à relação capital trabalho, foram os pescadores que realizam, também, outra atividade laboral não relacionada ao mar, já os trabalhadores que migraram para atividade aquícola possuem submissão menos acentuada da relação capital trabalho, conclusão auferida pelo desprendimento aos riscos financeiros dos aquicultores ao se lançarem a realizarem um novo empreendimento, com riscos maiores de fracasso do que introdução de novas atividades laborais, não ligadas ao mar, a atividade de pesca . De uma forma menos limitada, pode-se considerar que a comunidade de pescadores (em geral e na praia da Rasa, particularmente) desenvolveu e ainda desenvolve mitos e ritos, estes adaptados aos fluxos de transformações temporais, mas que interferem diretamente na dinâmica desta comunidade, fatos observados no dia a dia da comunidade pesqueira e nas transformações e manutenções das técnicas de pesca praticadas na região, com utilização, para a pesca de conhecimentos tradicionais (anzol, remos) e conhecimentos científicos (previsão do tempo). No que se refere a interferência das atividades macroambientais, tanto a atividade petrolífera, como a especulação imobiliária e o turismo, interferem direta e indiretamente a realidade da comunidade aquícola e pesqueira da Praia Rasa, Armação dos Búzios-RJ. Fator observado na dinâmica da comunidade local e também demonstrado nos dados do IBGE (2010), que apontam para um PIB, em Armação dos Búzios, com maiores fatias do setor industrial e para um aumento da população, no mesmo município, em crescimento proporcional superior as médias estaduais e nacionais. Isto indica crescimento da demanda imobiliária em relação à oferta, afetando a disponibilidade de áreas para moradias dos pescadores e alterando a disponibilidade de recursos da população de uma forma geral.

\section{Referências}

ALVARES, L.C. A questão Metropolitana e as Políticas Oficiais no Brasil:

Evolução e o Caso da Região Metropolitana de Belo Horizonte (RMBH). In: CONGRESSO BRASILEIRO DE DIREITO URBANÍSTICO, 1, 2001, Brasil. Anais... Brasil: IBDU, 2001.

ALVIM, R. G. As condições de vida dos pescadores artesanais de Rua da Palha. Acta Scientiarum : Human and Social Sciences, v.34, n.1, p.101-110, jan./jun. 2012. BRASIL-MINISTÉRIO DO TURISMO. Estatísticas Básicas do Turismo, Brasília, 2013. Disponível em <www. turismo.gov.br>. Acesso em: 16 abr. 2014. 
CALVOSA, M. Gerência de Vendas. 1. ed. Rio de Janeiro: Fundação CECIERJ, 2010.

CASTELLS, M. A Questão Urbana. Rio de Janeiro: Paz e Terra, 2000.

CORIOLANO, L. N. M. T.(Org.).Turismo com Ética. Fortaleza: Funece, 1998.

DIEGUES, A. C. A sócio-antropologia das comunidades de pescadores marítimos no brasil. Etnográfica, v.3, n.2, p. 361-375, mai./ago. 1999.

DUMAZEDIER, J. Sociologia empírica do lazer. 3. ed. São Paulo: Perspectiva SESC. HARVEY, D. A justiça social e a cidade. São Paulo: Hucitec, 1980.

HERCULANO, S. Desenvolvimento local, responsabilidade sócioambiental e royalties: a Petrobrás em Macaé (RJ). Rio de Janeiro, 2010. Disponível em: <http://www.uff.br/macaeimpacto/OFICINAMACAE/textos00.html >. Acesso em: 20 out. 2014.

INSTITUTO BRASILEIRO DE GEOGRAFIA E ESTATÍSTICA. Censo 2010. 2010. Disponível em: 〈http://www.ibge.gov.br/>. Acesso em: 06 ago. 2014.

LEFEBVRE, H. Espaço e Política. Belo Horizonte: Editora UFMG, 2008.

LÉVI-STRAUSS, C. O pensamento selvagem. 2. ed. Campinas: Papirus, 1997.

MACIEL, A. B. C.; LIMA, J. D.; LIMA, Z. M. C. Mudanças antrópicas e naturais da paisagem coteira da praia de Ponta Negra, Natal/RN, Brasil. In: ENCUENTRO DE GEÓGRAFOS DA AMÉRICA LATINA, 14, 2013, Perú. Anais... Perú: UGI, 2013.

MARX, K. Manuscritos Econômico-Filosóficos. São Paulo: Boitempo, 2004.

MARX, K. Os manuscritos econômicos e filosóficos. Lisboa: Edições 70, 1964.

MORETTI, S. Qualidade de vida no trabalho x auto-realização humana. Instituto

Catarinense de Pós-Graduação, Florianópolis, 2005. Disponível em:

<http://www.icpg.com.br/artigos/rev03-12.pdf>. Acesso em: 17 set. 2014.

PESSOA, P. F. A. Gestão Agroindustrial. Fortaleza: Embrapa Agroindústria Tropical. 2003.

RAMALHO, C. W. N. Embarcadiços do encantamento: trabalho como arte, estética e liberdade na pesca artesanal de Suape, PE. 2007. 300f. Tese (Doutorado), Universidade Estadual de Campinas. Programa de Pós-Graduação em Ciências Sociais, Campinas, 2007.

SANTOS, J. C.; PESSOA, V. L. S. A relação capital x trabalho e seus desdobramentos na agroindústria canavieira macrorregião geográfica de presidente prudente (SP): uma reflexão. ENCONTRO DE GRUPOS DE PESQUISA, 2, 2006, Uberlândia. Anais... Uberlândia: UFU, 2006.

SELlTIZ, C.; et al. Métodos de Pesquisa nas Relações Sociais. São Paulo: Pedagógica e Universitária Ltda., 1987.

TOLBERT, P. S.; ZUCKER, L. G. A institucionalização da teoria institucional. In:

CLEGG, S. R.; ARDY, C.; NORD, W. R. (Orgs.). Handbook de estudos organizacionais. São Paulo: Atlas, 1998. p. 196-219.

TRIVIÑOS, A. N. S. Introdução à pesquisa em ciências sociais: a pesquisa qualitativa em educação, São Paulo: Atlas, 1992. 